\title{
Electrochemical Detection of Vitamin D2 and D3 Based on a Au- Pd Modified Glassy Carbon Electrode
}

\author{
Kun Men ${ }^{1}, Y u$ Chen $^{2}$, Jinbiao Liu ${ }^{3}$ and Dianjun $\mathrm{Wei}^{1, *}$ \\ ${ }^{1}$ Department of clinical laboratory, The Second hospital of Tianjin Medical University, Tianjin, \\ 300211, China \\ ${ }^{2}$ Department of Endocrinology, The Second hospital of Tianjin Medical University, Tianjin, 300211, \\ China \\ ${ }^{3}$ Instrumental Analysis Center, School of Chemistry and Chemical Engineering, Tianjin University \\ of Technology, Tianjin, 300384, China \\ *E-mail: dianjunwei0912@163.com
}

doi: $10.20964 / 2017.10 .15$

Received: 20 June 2017 / Accepted: 25 July 2017 / Published: 12 September 2017

In this work, the synthesis of AuPd bimetallic nanocrystals in an aqueous solution using a stabilizing agent and a reductant of triblock copolymer P123 and ascorbic acid, respectively, was proposed. Vitamins $D_{2}$ and $D_{3}$ were electrochemically detected in a mixed organic/water solution based on a glassy carbon electrode (GCE) modified by AuPd. The electrocatalytic response of D vitamins on the GCE surface was greatly affected by the organic/water ratio of the mixture. In the presence of the support electrolyte (lithium perchlorate), vitamins $\mathrm{D}_{2}$ and $\mathrm{D}_{3}$ exhibited well-defined peaks when the ethanol/water ratio was $40 \% / 60 \%$. This work also suggested the high sensitivity of the GCE toward the detection of vitamins $\mathrm{D}_{2}$ and $\mathrm{D}_{3}$. During the detection of vitamin $\mathrm{D}$, vitamins $\mathrm{A}, \mathrm{K}$ and $\mathrm{E}$ showed no obvious interference effects.

Keywords: Bimetallic nanocrystals; Vitamin D; Electrochemical determination; glassy carbon electrode; Osteoporosis

\section{FULL TEXT}

(C) 2017 The Authors. Published by ESG (www.electrochemsci.org). This article is an open access article distributed under the terms and conditions of the Creative Commons Attribution license (http://creativecommons.org/licenses/by/4.0/). 